\title{
Didática e metodologias ativas de aprendizagem: o que constam no projeto político
} pedagógico e revelam $o$ fazer docente?

\author{
Rosimeri Jorge da Silva \\ rosejorgesilva@gmail.com \\ Universidade Federal de Santa Catarina - UFSC \\ Jilvania Lima dos Santos Bazzo \\ jilvania.bazzo@ufsc.br \\ Universidade Federal de Santa Catarina - UFSC
}

Resumo: Este artigo resulta de pesquisa bibliográfica e etnográfica, com uma abordagem exploratória, de ordem qualitativa com a obtenção de dados quantitativos e qualitativos, cujo objetivo é problematizar a organização da prática docente e as suas implicações na implementação do projeto político pedagógico (PPP) e, consequentemente, as metodologias de aprendizagem. Este estudo visa estabelecer uma relação entre a docência, a formação inicial e a constituição do PPP, como espaços coletivos de construções de identidades, que definem a função social da escola. Nessa relação, a Didática ocupa o lugar de problematização, da criação e da invenção sobre as práticas docentes e o projeto de escola. Tomando como referência as concepções que fundamentam o PPP. A partir de nossa experiência na área de formação de professores da educação básica, evidenciamos os resultados preliminares que nos mostram um distanciamento entre a gestão da escola e o fazer pedagógico, pois o gestor tem uma grande e diversa função administrativa, dispondo de tempo insuficiente, para compreender e atuar nas questões que envolvem o ensino e a aprendizagem, ao mesmo tempo em que há também esse distanciamento entre o PPP e o fazer docente.

Palavras-chave: Docência; Didática; Projeto Político Pedagógico; Formação de professores; Metodologias ativas.

\section{Introdução}

Desde que iniciamos o trabalho com formação de professores da Educação Básica, aproximadamente 30 anos atrás, nós vimos nos questionando sobre os processos de aprendizagem e de ensino para o desenvolvimento de um estudante crítico, como comumente se prevê em um Projeto Político Pedagógico (PPP) e o que de fato o professor precisa fazer, saber e mobilizar dentro e fora de sala de aula . A partir dessa problemática,

\section{2) VIA SEGC}


outras tantas questões surgiram, como, por exemplo: como o professor ou a professora consegue perceber o que é necessário para a formação crítica e trilhá-la com seus estudantes? Quais metodologias foram utilizadas? Quais os papeis atribuídos aos estudantes no processo de construção do conhecimento?

Durante esta caminhada longa, tivemos contato com muitos professores de diversas áreas, pedagogos e licenciados, cada qual carregava a sua marca histórica de formação, que para escola trazia esta trajetória, às vezes, carregada de significados e processos criativos. Esses profissionais se apresentavam por vezes comprometidos com o coletivo e mediadores dos conhecimentos ou destituídos de coletivos e cheios de ego de professor. Porém, o que mais saltava aos olhos era a diferença que se fazia entre os conceitos de ensino e aprendizagem.

Um distanciamento se apresentava entre estes dois conceitos, com muita frequência, nas práticas e nos discursos, quando se ouvia "ele não aprende porque não quer" ou "eu ensinei, mas ele não quis" ou "eu ensino, ensino e ele não aprende". Essas falas nos inquietavam e nos inquietam até hoje, porque elas ainda não deixaram de existir. Outras falas que nos preocupam, tanto quanto estas são: "este PPP não serve para nada", "este texto do PPP é muito teórico", ou "não consigo levar isso para sala de aula", "para que serve escrever estes conceitos todos no PPP?". Alguns desses posicionamentos teóricos e práticos se referiam aos conceitos de infâncias, juventudes, juventude trabalhadora, ensino noturno, diversidade entre outros. Nesta caminhada, acompanhamos ainda vários estágios acadêmicos e professores em formação, que buscavam, ao se constituir como docentes, fazer a diferença. Esses traziam para a organização do ensino, na didática das aulas, os princípios da Didática, seus fundamentos, conceitos e conteúdos, buscando consolidar sua formação e a função social de ensinar os conhecimentos historicamente elaborados.

Pretendemos compreender qual o papel da Didática e as metodologias de aprendizagem na implementação do Projeto Político Pedagógico e suas contribuições para a formação inicial dos professores da Educação Básica, buscando, com este trabalho, entender a necessidade da construção coletiva dos objetivos, conteúdos, métodos e formas de gestão do ensino, e que estes possam ser elaborados a partir do projeto de escola, aquele que construiria/formaria um determinado cidadão, trazendo para o debate as experiências sociais e históricas dos estudantes, professores, pais e funcionários.

Considerando que Libâneo (2012) reforça que o objetivo de ensinar requer que o professor medeie o conhecimento elaborado historicamente a partir dos aportes teóricos e metodológicos da Didática e de outros conhecimentos da área das ciências da educação,

\section{-2: VIA SEGC}


diante destas constatações, destacamos a necessidade de pesquisas que aprofundem estudos sobre os processos de organização didática, procurando entender as metodologias ativas e a Didática frente ao fazer pedagógico e a implementação do PPP. Como Galeffi (2012, p. 62) brilhantemente definiu "cada um de nós é o poeta do ethos de sua paixão mais radical: a trans-formação humana continuada”. Os docentes e suas didáticas são a possibilidade real, porém é possível que ainda exista uma distância entre o escrito no papel e a didática praticada em cada sala de aula.

\section{Método}

Esta pesquisa atende aos princípios de uma abordagem exploratória, de ordem qualitativa e do tipo etnográfico, definida por Neves (1996, p.1) como a "obtenção de dados descritivos mediante contato direto e interativo do pesquisador com a situação objeto de estudo", pois a subjetividade está sempre presente no objeto analisado e o foco também está nas particularidades e experiências dos docentes, bem como em suas práticas. É o que Galeffi (2012, p. 62-63) define como: concentrar a atenção na busca de um tempo registrado na memória do vivido" e "representar em ideias o vivido". A compreensão de pesquisa qualitativa adotada opera com o conceito de realidade como construto social complexo, difuso e multifacetado:

A realidade é uma construção social da qual o investigador participa e, portanto, os fenômenos só podem ser compreendidos dentro de uma perspectiva holística, que leve em consideração os componentes de uma dada situação em suas interações e influências recíprocas, o que exclui a possibilidade de se identificar relações lineares de causa e efeito e de se fazer generalizações de tipo estatístico [...], para os qualitativos, conhecedor e conhecido estão sempre em interação e a influência dos valores é inerente ao processo de pesquisa. (ALVES, 1991, p. 55).

Segundo Chizzotti (2003, p. 221):

O termo qualitativo implica uma partilha densa com pessoas, fatos e locais que constituem objetos de pesquisa, para extrair desse convívio os significados visíveis e latentes que somente são perceptíveis a uma atenção sensível e, após este tirocínio, o autor interpreta e traduz em um texto, zelosamente escrito, com perspicácia e competência científicas, os significados patentes ou ocultos do seu objeto de pesquisa.

A escolha da abordagem qualitativa se dá por ser a mais adequada para atender às necessidades da pesquisa e seus objetivos que se reforça em Chizzotti (2001, p. 84) ao afirmar que na pesquisa qualitativa todos os fenômenos são importantes: "é necessário

\section{- VIS VIA SEGC}


encontrar o significado manifesto e o que permaneceu oculto. Todos os sujeitos são igualmente dignos de estudo, todos são iguais, mas permanecem únicos".

Os autores Bogdan e Biklen (1994, p. 47) também ratificam a vertente por nós ora eleita:

Na pesquisa qualitativa, a fonte direta de dados é o ambiente natural e o investigador qualitativo é seu instrumento principal, ou seja, o investigador "freqüenta o local de estudo", porque entende que as ações podem ser mais bem compreendidas quando observadas no ambiente habitual.

Ainda segundo esses autores, a pesquisa qualitativa possui cinco características, que são fundamentais como: a fonte direta de dados é o ambiente natural e o investigador qualitativo é seu instrumento principal; a descritiva, porque os dados recolhidos são apresentados em forma de palavras ou imagens e não de números; o interesse, que é maior pelo processo do que pelos resultados; a análise dos dados, que se caracteriza de forma intuitiva na intenção de responder ao problema proposto e a importância ao significado.

O intuito é alcançar uma amostra em nível estadual, escolhendo escolas que possuam o PPP construído coletivamente, em diferentes regiões do Estado de Santa Catarina, além de acompanhar e pesquisar, no mínimo, quatro professores de cada escola. A proposta se justifica pela necessidade de relacionar as práticas docentes com a implementação do PPP, observando, sobretudo, as metodologias ativas e os dispositivos pedagógicos necessários para favorecer o desenvolvimento da formação crítica dos estudantes, bem como a contribuição da Didática para essa formação.

Pretendemos, a partir desse horizonte de sentidos da abordagem qualitativa, identificar nas práticas docentes e suas formas didáticas, as implicações da formação inicial e os pressupostos do PPP, utilizando os seguintes procedimentos metodológicos: entrevistas semi-estruturadas, que, segundo Gil $(1999$, p.11) “é bastante adequada para obtenção de informações acerca do que as pessoas sabem, creem, esperam, sentem ou desejam"; questionários, revisão bibliográfica, análise de documentos, diário de campo, observação participante do processo de elaboração dos planejamentos, participação em reuniões de estudo e replanejamento do PPP, encontros com professores, alunos, gestores e técnicos pedagógicos com conversas informais, com intuito de recolher informações prévias sobre o campo de interesse antes e após as entrevistas semi-estruturadas, possibilitando ao pesquisador informações que possibilitem uma averiguação e uma comparação entre o

\section{- VIA GEGC}


discurso e a prática efetiva na didática utilizada pelo professor e as contribuições da Didática da formação inicial.

As entrevistas-semi estruturadas e os questionários com os professores, o gestor, os coordenadores pedagógicos e estudantes visam compreender o papel da Didática na implementação do projeto de escola. Diante das inúmeras produções nas áreas que envolvem a pesquisa, acreditamos ser importante fazer uma revisão bibliográfica para aprofundar os estudos sobre os conceitos-chave levantados, visto que o contexto histórico de produção de conhecimento das áreas em estudo está em constante aprofundamento e reflexão. Importa registrar ainda que se faz muito importante também o tratamento e análise de informações constantes em documentos, para compreender e caracterizar o período em estudo, na forma de registros, atas, imagens, relatórios, linguagens escritas e orais, pois, segundo Severino (2007), se trata de nós compreendermos criticamente o sentido manifesto ou oculto das comunicações.

A observação da prática docente, em sala de aula, torna-se um instrumento necessário para levantar o lugar da Didática na implementação do PPP. Segundo Gil (1999 p.119), a observação constitui elemento imprescindível para a pesquisa, desde a formulação do problema, passando pela construção de hipóteses, coleta, análise e interpretação dos dados. As observações diretas fornecerão subsídios para o contexto do mundo real, onde o pesquisador somente observa o que está acontecendo, como também permitem que o observador chegue mais perto da "perspectiva dos sujeitos", um importante alvo nas abordagens qualitativas. (LUDKE, 2006, p.26).

Por sua vez, o registro em diário de campo é um dos procedimentos metodológicos que possibilita ao pesquisador efetivar as características da pesquisa qualitativa, para que não passe somente pela lembrança do pesquisador, principalmente quando as falas, os símbolos e impressões dos momentos ultrapassem os outros instrumentos de coleta, além de possibilitar a caracterização dos momentos acontecidos. "Trata-se de abrir o olhar ao estranhamento, ao deslocamento do conhecido para o desconhecido, que não é só o outro sujeito com quem interagimos socialmente, mas também o outro que habita em nós mesmos." (SOUZA e FLEURI, 2003, p. 69) e que Galeffi (2012, p. 65) define como: "existem meios de expressão e indicação do fluxo da vigência do vigente sem que seja preciso que tais meios percam sua ação de indicação e se torne objetos absolutos em si mesmos, independentemente de qualquer coisa". Através dos relatos e das observações realizadas junto às escolas escolhidas, serão relacionadas os pontos principais e fundamentá-

\section{- VIA GEGC}


los na literatura especializada, dando ênfase àqueles que responderem as indagações iniciais, foco desse estudo.

\section{Discussão e resultados parciais}

Como cada situação é sempre única, trazemos Libâneo (2011) para iniciarmos as discussões em torno da Didática e das questões de pesquisa levantadas anteriormente:

Como mediação escolar dos objetivos e conteúdos de ensino, a didática investiga as condições e formas que vigoram ensino e, ao mesmo tempo, os fatores reais (sociais, políticos, culturais, psico sociais) condicionantes das relações entre docência e aprendizagem [...] O processo didático de transmissão/assimilação de conhecimentos, habilidades e valores tem como culminância o desenvolvimento das capacidades dos alunos, de modo que assimile ativa e independentemente os conhecimento sistematizados ( p. 41)

Com esta afirmação de Libâneo, reforçamos que o PPP tem papel central na culminância do desenvolvimento das capacidades dos estudantes, pois ele é a expressão do pensamento, da linguagem e das atitudes do coletivo de professores e de todas as pessoas que compõem a unidade escolar. Deixamos esse aspecto em evidência para fortalecer/questionar a ideia de que todos os professores e as professoras quando entram em uma sala de aula, querem dar ou exercer boas aulas, ensinar e garantir a aprendizagem. As experiências que vivenciamos, nas mais diversas situações de ensino e realidades escolares, demonstram que os professores enfrentam diversos desafios em planejar suas aulas com possibilidades mínimas de efetivá-las e com isso garantir o ensino e, portanto, garantir a aprendizagem dos estudantes. Aqui abrimos espaço para discutir a formação docente e a complexidade da prática docente, frente aos desafios do cotidiano escolar. Libâneo (2002) retrata em sua fala que o saber-fazer, o planejamento, o manejo de classe, a capacidade de segurar uma sala de aula, de proporcionar estímulos variados aos estudantes e diferentes formas de trabalho criativo são competências que precisam ser aprendidas, e de alguma forma, ensinadas. Mas, como é isso? Aprender sem ensinar? E o que é o ensino? O que significa ensinar? E aprender? Serão metodologias de aprendizagem ativas?

Considerando a afirmação de Libâneo, trazemos Galeffi (2017, p.106) para problematizar as formas de ensinar nos cursos de formação de professores, "que os educadores estão sendo formados como se vivêssemos ainda no século da ilustração, das luzes da razão". Percebemos, ainda, que os problemas, na sua maioria, deixadas pela formação docente inicial, poderiam ou deveriam ser solucionados pela formação

\section{-2: VIA SEGC}


continuada, a partir do projeto coletivo de escola. Mas, como? Eis mais uma questão de

Didática a ser solucionada

Ao analisar estes pontos, em diversas situações, chegamos a conclusão que, se o PPP estiver bem estruturado e se for construído consciente e coletivamente com a participação de todos, pode vir a ser um instrumento que possa projetar as ações docentes na perspectiva de atender seus objetivos de ensino e possibilitar ao professor e à professora o alcance de suas demandas formativas. Que Galeffi (2017, p. 106) nos provoca ao enfatizar que: "a sociedade ainda não conhece o educador do século XXI porque ele tem que ser construído". Neste ponto, consideramos o papel do gestor escolar fundamental, como articulador de todos os processos que envolvem a escola e principalmente no que se refere à dimensão pedagógica, tendo claro que não é o único a refletir e pensar este processo, buscando coletivamente, segundo Galeffi (2017, p. 107) “desenhar outro papel do educador, que agora se inscreve em uma rede de aprendizagem colaborativa, com a intenção de encontrar a melhor mediação aprendente para cada singularidade".

Não falo de um fazer repetitivo, mas de uma capacidade criadora de enfrentar problemas, de descobrir soluções, de lidar com o imprevisto. A mudança das práticas organizacionais e de gestão, junto com o projeto pedagógico, podem produzir um impulsionamento dessa criatividade inovadora. Temos que mudar, mas precisamos saber como fazer essa mudança (LIBÂNEO, 2002, p.42).

O trabalho na escola é um trabalho conjunto dos especialistas, dos professores, alunos e funcionários. Não se admite mais hoje em dia o trabalho isolado do professor na sala de aula. Por essa razão, cresce em importância o projeto pedagógico da escola. O projeto pedagógico estabelece objetivos comuns, intenções comuns, uma proposta curricular comum e práticas escolares também decididas coletivamente. Uma de suas contribuições é a de garantir uma unidade de ação dos profissionais da escola (LIBÂNEO, 2002, p.132).

Os professores e professoras passam por vários tipos de escolas e conhecem algumas experiências diferenciadas, com sistemas seriados, ciclos, séries, anos, semestres, trimestres e tantas outras organizações. No entanto, a função social da escola ainda é um desafio, mesmo com todas as mudanças na sociedade, como as novas tecnologias, pois os sujeitos que a sociedade espera que a escola ajude a formar não são mais os mesmos; o resultado que a escola produz tem que ser diferente, segundo as exigências de uma sociedade em que as pessoas vão se constituindo no jogo de forças a que estão expostas.

\section{-2: VIA SEGC}


Neste contexto complexo e de tantas exigências, talvez a Didática da formação inicial dos professores necessite refletir o seu lugar na formação docente, para contribuir na construção de uma escola que queira se constituir como espaço de "resistência criativa" (GALEFFI, 2017), questionador do projeto social em curso e formador de crianças e jovens pensantes, criativos e generosos uns com os outros. De acordo com Veiga (1998), existem vários caminhos para construção de um projeto de escola, uma vez que ele retrata o entendimento e o percurso possível trilhado em cada uma das unidades escolares. É por este motivo que estudar o papel da Didática na implementação do PPP torna-se um imperativo, sobretudo perceber as metodologias ativas que estão nele inseridas.

A partir de nossas experiências podemos afirmar que, do modo como o PPP está posto para a escola e sua comunidade, pouco tem contribuído para que o professor e a professora organizem a didática de suas aulas, além de não ter percebido que o documento escrito pelas escolas (PPP) promova a interação entre as diversas áreas do conhecimento e suas práticas de ensino, principalmente para o estudante em formação. Ao contrário do que apresenta Gadotti (1994, p. 38) "o projeto significa lançar-se para a frente, antever o futuro. O projeto é, pois, um planejamento em longo prazo, atividade racional, consciente e sistematizada que as escolas realizam para traçarem a sua identidade." Ainda que no discurso o PPP tenha um lugar nas práticas docentes, fica claro que o que está sendo usado deste documento são a normas que regem as aulas e os comportamentos dos estudantes, além de uma definição mínima de currículo, muitas vezes copiado das Propostas Curriculares em curso.

Em nossos primeiros contatos informais com diretores escolares, nos diversos relatos, o que mais aparece é como estabelecer a relação com a comunidade escolar e como fazer com que os professores possam planejar suas aulas de forma a implementar o projeto de escola. Para ilustrar, um professor que trabalha o componente curricular de Matemática ou História, por exemplo, do $6^{\circ}$ ano ao Ensino Médio, prepara na maioria das vezes as mesmas estratégias didáticas para as diferentes faixas etárias, ignorando o texto do PPP que traz concepção de infância, criança, adolescente, jovem, jovem trabalhador entre outros conceitos e concepções amplamente discutidas ao longo das formações. Embora compreendam a importância do seu papel para a efetivação da função social da escola, o planejamento dos professores não contempla ações didáticas para atender às especificidades de cada faixa etária, seus marcadores identitários e o contexto social em que vivem. Verificamos um distanciamento entre o que está escrito no PPP e no fazer pedagógico.

\section{-2: VIA SEGC}


Nesse contexto, uma pergunta precisa ser feita: por que se faz necessário usar uma metodologia diferenciada quando se trabalha com uma criança de 10 anos ou com um jovem trabalhador, ou um adolescente de 17 anos? O que os cursos de licenciaturas estão ensinando frente a esses desafios? Para tentar responder essas e outras perguntas temos a hipótese que, para que haja interação entre o PPP e as práticas docentes, é preciso a construção coletiva do PPP, com a participação de toda comunidade escolar, construindo o sentido da escrita e transformando o documento burocrático em um projeto possível de ser apropriado por todos, pelos que chegam depois e pelos que estão em formação, e, neste caso, a gestão escolar e as agências formadoras têm um papel de interlocutor no processo, possibilitando espaços de interação entre os pares. Na visão dos professores os projetos produzidos pelas escolas ainda não atendem às suas necessidades, pois os textos se tornam difíceis de serem compreendidos e a realidade escolar é outra.

Mas, e nas escolas onde o PPP foi construído de forma consciente e coletivamente? O que constam no PPP em ternos de metodologias ativas e dispositivos pedagógicos para fins de ensino e aprendizagem? E o que revelam as práticas docentes?

Investigar o sentido do PPP para o professor, suas práticas docentes e a Didática na formação inicial é uma possibilidade de estudo, uma problemática que nos impulsiona e pode gerar pesquisas sobre o papel da Didática na implementação do PPP, principalmente quando percebemos a importância da Didática na efetivação da função social da escola. Como ressalta Severino (2007), a temática a ser estudada deve ser uma problemática vivenciada pelo pesquisador, dizendo-lhe respeito no nível da avaliação, da relevância e da significação dos problemas, tendo em vista o universo que o envolve, como ato político, considerando, então, que, neste âmbito, não existe neutralidade. Refletir sobre o papel da Didática, neste processo, é uma possibilidade de desenvolver um novo olhar para/sobre a escola e seu projeto e uma nova prática de construção de PPP pode surgir, com a finalidade de articular as práticas docentes com os desejos de um coletivo, expressos em seu projeto de escola.

Nesta direção, Veiga (1996; 1998) e Libâneo (2002) nos fazem perceber que o PPP deve ser visto como um processo permanente de reflexão e de discussão dos desafios da escola, tendo por base a construção de um processo democrático de decisões que visa superar as relações competitivas, corporativas e autoritárias, rompendo com a rotina burocrática no interior da escola. Portanto, ao valorizar a formulação coletiva do projeto pedagógico, como expressão de propósitos e práticas que se criam e se desenvolvem na

\section{-2: VIA SEGC}


escola e nas salas de aula, significa articular o currículo e a Didática à organização do trabalho escolar.

Diante destes aspectos, surgem algumas questões: Qual é o lugar da Didática na construção do PPP? É possível que o documento escrito coletivamente (PPP) reflita os anseios dos professores e estudantes no grande desafio de ensinar e aprender? Como planejar as aulas a partir do projeto de escola escrito coletivamente? Como aliar os desejos da sociedade com as práticas docentes? E como a formação inicial pode contribuir com esse processo?

Libâneo (2002, p. 131) nos ajuda a refletir sobre essa questão, afirmando o seguinte:

Não estou falando de uniformidade. Estou falando da possibilidade de uma negociação entre os profissionais da escola de uma pauta comum de pensamento e ação em torno de objetivos e práticas escolares. Essa pauta implica um mínimo de consenso em torno de assuntos como: as funções sociais da escola, expectativas quanto à formação dos alunos, os objetivos do ensino nesta escola, a função dos conteúdos, métodos e avaliação, as formas de gestão.

Posteriormente, como da utopia nascem algumas convicções, acreditamos na construção coletiva de um projeto de escola como também na possibilidade de materialização de ações planejadas pelas decisões acordadas no plano coletivo, como tão bem anunciou Libâneo. Desse modo, saber que é preciso, diante das divergências e dos interesses incomuns, encontrar consenso tomando como referência "as funções sociais da escola, expectativas quanto à formação alunos, os objetivos do ensino...” (LIBÂNEO, 2002, p. 131).

Se a função principal da escola, segundo Sforni (2012, p.469) "é a socialização do conhecimento produzido historicamente e consolidado nos diversos conteúdos curriculares, cabendo ao professor o domínio desse conhecimento, bem como dos meios para torná-lo acessível aos estudantes". Ela precisa expressar as formas de como vai alcançar seu objetivo e garantir sua função social, que é reforçada por Lück (2009):

Qual o principal objetivo da escola? A resposta lógica a essa questão é a de que os alunos aprendam e tenham a oportunidade de desenvolver o seu potencial e as habilidades necessárias para que possam participar ativamente dos contextos sociais de que fazem parte, tanto aproveitando $o$ seu acervo sociocultural e produtivo, como contribuindo para a sua expansão. Aprendizagem e formação dos alunos são, pois, o foco do trabalho escolar (p. 94)

\section{-2: VIA SEGC}


Para nós, diante do que foi discutido até o presente momento, o PPP é o projeto que define coletivamente os anseios da escola e desta sociedade. Porém, percebemos também que esse mesmo documento que registra esses anseios, fica esquecido numa gaveta. Esse, muitas vezes, é confrontado pela autonomia docente, deixando o vazio tomar conta do espaço da reflexão, que fica diluído nas diversas práticas em cada sala de aula.

[...] o papel da escola, facilmente reconhecido e indicado por todos. A sua realização, porém, apenas se dá na medida em que todos e cada um dos profissionais que atuam na escola entendam e assumam esse papel como seu. Afinal, uma escola é uma organização social constituída e feita por pessoas. Esse processo, por certo, por sua complexidade, dinâmica e abrangência, demanda uma gestão específica que envolve a articulação entre concepções, estratégias, métodos e conteúdos, assim como demanda esforços, recursos e ações, com foco nos resultados pretendidos. Esse processo de articulação representa a gestão pedagógica. (LÜCK, 2009, p 94).

No nosso entendimento essa gestão pedagógica acontece na sala de aula, mas também no espaço da gestão escolar, construindo um compromisso coletivo, demonstrando que o PPP é o documento que possibilita essa articulação e pode garantir que a gestão pedagógica aconteça de forma a viabilizar o ensino; com isso garantir a aprendizagem.

[...] as condições da prática do professor no âmbito organizativo demarcam os caminhos de seu pensamento e de sua ação. É preciso, portanto, um sistema de gestão e organização voltado para a participação nas decisões e construção coletiva de práticas docentes. A participação coletiva é uma exigência ligada à própria natureza da ação pedagógica. É daí que nasce a proposta educacional ou o projeto pedagógico da escola (LIBÂNEO, 2002, p. 41).

É nesse processo que a Didática tem seu espaço para discutir as questões das práticas pedagógicas, respondendo as perguntas que ecoam em todo contexto escolar. Como ensinar para jovens e crianças que habitam as escolas públicas estaduais de Santa Catarina em suas diversas configurações, que se constituem, dependendo do lugar, do tempo histórico e de seus marcadores identitários como gênero, classe social, raça/cor? Como a Didática, oferecida nos cursos de formação dos professores, contribui para efetivá-los? Quais as metodologias (ativas) aparecem nesses documentos? E o que revelam o fazer docente?

\section{-2 VIA QEGC}




\section{Conclusão}

Considerando que se trata de uma pesquisa em andamento no programa de PósGraduação da Universidade Federal de Santa Catarina, são questões em aberto e sua resolução foi iniciada com este trabalho. A partir de nossa experiência na área de formação de professores da educação básica, evidenciamos que há um distanciamento entre a gestão da escola e o fazer pedagógico, pois o gestor tem uma grande e diversa função administrativa, não sobrando tempo para compreender e atuar nas questões que envolvem o ensino e a aprendizagem, ao mesmo tempo em que há também esse distanciamento entre o PPP e o fazer docente. Observamos que os docentes já compreendem a importância de seu papel na efetivação do projeto da escola, mas na maioria das escolas, existe um distanciamento entre o documento escrito e a prática docente. Neste caso, os conhecimentos do campo da Didática não são acionados com vistas à intervenção pedagógica em situação de aprendizagem, a partir do projeto que a escola produziu coletivamente.

Defendemos ao longo do texto que este é um espaço privilegiado para aprofundarmos os estudos sobre o papel da Didática e sua relação com a efetivação de projetos de escola em curso, especialmente no tocante às metodologias (ativas) de aprendizagem. Entendemos que esse debate em torno das questões metodológicas traz contribuições importantes para o campo da educação, no sentido de ajudar a projetar possibilidades ainda não pensadas. Outrossim, proporciona questionar as forças que atravessam os processos escolares, carregados de seus significados sociais, históricos e culturais, compreendendo que o caminho o qual escolhemos para fazer esta discussão sugere a incorporação de questões epistemológicas, cujas práticas precisam ser revisitadas ou atravessadas por um olhar atento, sensível e pautado em critérios das ciências humanas.

Isto posto, nossa expectativa é contribuir para ampliar as reflexões sobre processos escolares a partir da análise da prática docente e sua contribuição na configuração ou consolidação dos Projetos Políticos Pedagógicos. Quiça, em tempos difíceis, possamos enfrentar os fantasmas, os dramas e os desafios como quem corajosamente espera os ventos e as tempestades passarem pela certeza que haverá o amanhã e, junto com ele, o arco-íris aparecerá.

\section{Referências}

ALVES, A. J. O planejamento de pesquisas qualitativas em educação. Caderno de Pesquisa. São Paulo, n. 77, p. 53-61, 1991.

BECKER, H. S. Métodos de pesquisa em ciências sociais. São Paulo: Hucitec, 1994.

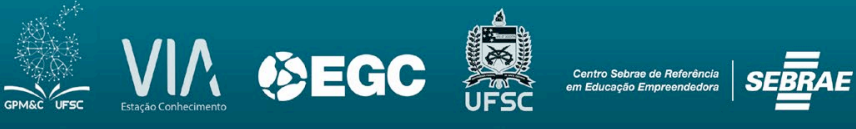


BOGDAN, R.; BIKLEN, J. Investigação qualitativa em educação: uma introdução à teoria e aos Métodos. Porto: Porto, 1999.

CHIZZOTTI, A. A pesquisa qualitativa em ciências humanas e sociais: evolução e desafios. Revista Portuguesa de Educação. Braga-PT, v. 16, n. 2, p. 221-236, 2003.

. Pesquisa em Ciências Humanas e Sociais. São Paulo: Cortez, 2001.

GADOTTI, M. Pressupostos do projeto pedagógico. Cadernos Educação Básica - O projeto pedagógico da escola. Atualidades pedagógicas. MEC/FNUAP, 1994.

GALEFFI, D. A. Didática filosófica mínima. Ética do fazer-aprender a pensar de modo próprio e apropriado como educar transdisciplinar. Salvador: Quarteto Editora, 2017.

- Po(éticas) da formação: éticas e estéticas na trans-formação humana emergente. Divertimento poético polilógico. In: PIMENTEL, A.; GALEFFI, D.; MACEDO, R. S. Po(éticas) da formação: experimentações éticas e estéticas no acontecer formacional. Salvador, EDUFBA, 2012, p. 61-148.

GIL, A. C. Métodos e técnicas de pesquisa social. São Paulo: Atlas, 1999.

LUDKE, M.; ANDRÉ, M. E. D. A. Pesquisa em educação: abordagens qualitativas. São Paulo: EPU, 2006.

LÜCK, H. Dimensões de gestão escolar e suas competências. Curitiba: Positivo, 2009.

LIBÂNEO, J. C. As relações "dentro-fora" na escola ou as interfaces entre práticas socioculturais e ensino. In: LIBÂNEO, J. C.; ALVES, N. (Orgs.). Temas de pedagogia: diálogos entre didática e currículo. Sao Paulo: Cortez, 2012, p. 333-349.

Didática e o Trabalho Docente: a mediação didática do professor nas aulas. In: LIBÂNEO, J. C.; SUANNO, M. V . R.; LIMONT A, S. V. (Orgs.). Concepções e práticas de ensino num mundo em mudança: diferentes olhares para a Didática. Goiânia: CEPED/Editora PUC Goiás, 2011.

Didática: velhos e novos temas. Edição do autor, 2002.

NEVES, J. L. Pesquisa qualitativa: características, usos e possibilidades. Caderno de pesquisas em administração, São Paulo, v.1, n. 3, p. 1-5, 1996.

SAVIANI, N. Saber escolar, currículo e didática: problemas da unidade conteúdo/método no ensino. Campinas-SP: Autores Associados, 2003. (Coleção educação contemporânea). SEVERINO, A. J. Metodologia do trabalho científico. São Paulo: Cortez, 2007.

SFORNI, M. S. Formação de professores e os conhecimentos teóricos sobre docência. In. LIBÂNEO. J. C., ALVES, N. (Orgs). Temas de pedagogia: diálogos entre didática e currículo. São Paulo: Cortez, 2012, p. 469-488. 
SOUZA, Ma . I. P.; FLEURI, R. M. Entre limites e limiares de culturas: educação na perspectiva intercultural. In: FLEURI, R. M. (Org.) Educação Intercultural: mediações necessárias. Rio de Janeiro: DP\&A, 2003, p.53-84.

VEIGA, I. P. A. Perspectivas para reflexão em torno do projeto político-pedagógico. In: VEIGA, I. P. A.; RESENDE, Lúcia G. de (Orgs.). Escola: espaço do projeto políticopedagógico. Campinas, SP: Papirus, 1998.

; FONSECA, M. (Orgs.). As dimensões do projeto político-pedagógico.

Campinas, SP: Papirus, 2001. 